\title{
CORRIGENDUM
}

\section{Contemporary management of men with high-risk localized prostate cancer in the United States}

AB Weiner, RS Matulewicz, EM Schaeffer, SL Liauw, JM Feinglass and SE Eggener

Prostate Cancer and Prostatic Diseases (2017) 20, 442. doi:10.1038/pcan.2017.35

Correction to: Prostate Cancer and Prostatic Diseases (2017) 20, 283-288; advance online publication, 20 June 2017; doi:10.1038/ pcan.2017.5
In Table 2 of the published article, the title of the fourth row, 'PSA at diagnosis', was incorrect. The correct title is 'Log of PSA at diagnosis'. The author regrets the error. 